\title{
Flexible Electronics: Status, Challenges and Opportunities
}

\author{
Daniel Corzo, Guillermo Tostado-Blázquez and Derya Baran* \\ Division of Physical Science and Engineering, KAUST Solar Center, King Abdullah University of Science and Technology (KAUST), \\ Thuwal, Saudi Arabia
}

Keywords: flexible electronics, stretchable, printing, healable electronics, electronic device, optoelectronic, device, soft robotics, solar cell, transistor, thermoelectric, sensors

The concept of flexible electronics has been around for several decades. In principle, anything thin or very long can become flexible. While cables and wiring are the prime example for flexibility, it was not until the space race that silicon wafers used for solar cells in satellites were thinned to increase their power per weight ratio, thus allowing a certain degree of warping. This concept permitted the first flexible solar cells in the 1960s (Crabb and Treble, 1967). The development of conductive polymers (Shirakawa et al., 1977), organic semiconductors, and amorphous silicon (Chittick et al., 1969; Okaniwa et al., 1983) in the following decades meant huge strides toward flexibility and processability, and thus these materials became the base for electronic devices in applications that require bending, rolling, folding, and stretching, among other properties that cannot be fulfilled by conventional electronics (Cheng and Wagner, 2009) (Figure 1).

Presently there is great interest in new materials and fabrication techniques which allow for highperformance scalable electronic devices to be manufactured directly onto flexible substrates. This interest has also extended to not only flexibility but also properties like stretchability and healability which can be achieved by utilizing elastomeric substrates with strong molecular interactions (Oh et al., 2016; Kang et al., 2018). Likewise, biocompatibility and biodegradability has been achieved through polymers that do not cause adverse effect to the body and can be broken down into smaller constituent pieces after utilization (Bettinger and Bao, 2010; Irimia-Vladu et al., 2010; Liu H. et al., 2019). This new progress is now enabling devices which can conform to complex and dynamic surfaces, such as those found in biological systems and bioinspired soft robotics.

These next-generation flexible electronics open up a wide range of exciting new applications such as flexible lighting and display technologies for consumer electronics, architecture, and textiles, wearables with sensors that help monitor our health and habits, implantable electronics for improved medical imaging and diagnostics, as well as extending the functionality of robots and unmanned aircraft through lightweight and conformable energy harvesting devices and sensors. While conventional electronics are very capable of these functions, flexible electronics are intended to expand the mechanical features to adhere to novel form factors through hybrid strategies, or as standalone solutions where the application does not require high computation power, intended to be highly robust to deformation, low cost, thin, or disposable. The definition of flexibility differs from application to application. From bending and rolling for easier handling of large area photovoltaics, to conforming onto irregular shapes, folding, twisting, stretching, and deforming required for devices in electronic skin, all while maintaining device performance and reliability. While early progress and many important innovations have already been achieved, the field of flexible electronics has many challenges before it becomes part of our daily life. This represents a huge opportunity for scientific research and development to rapidly and considerably advance this area (Figure 2). In this article the status, key challenges and opportunities for the field of nextgeneration flexible devices are elaborated in terms of materials, fabrication and specific applications. 


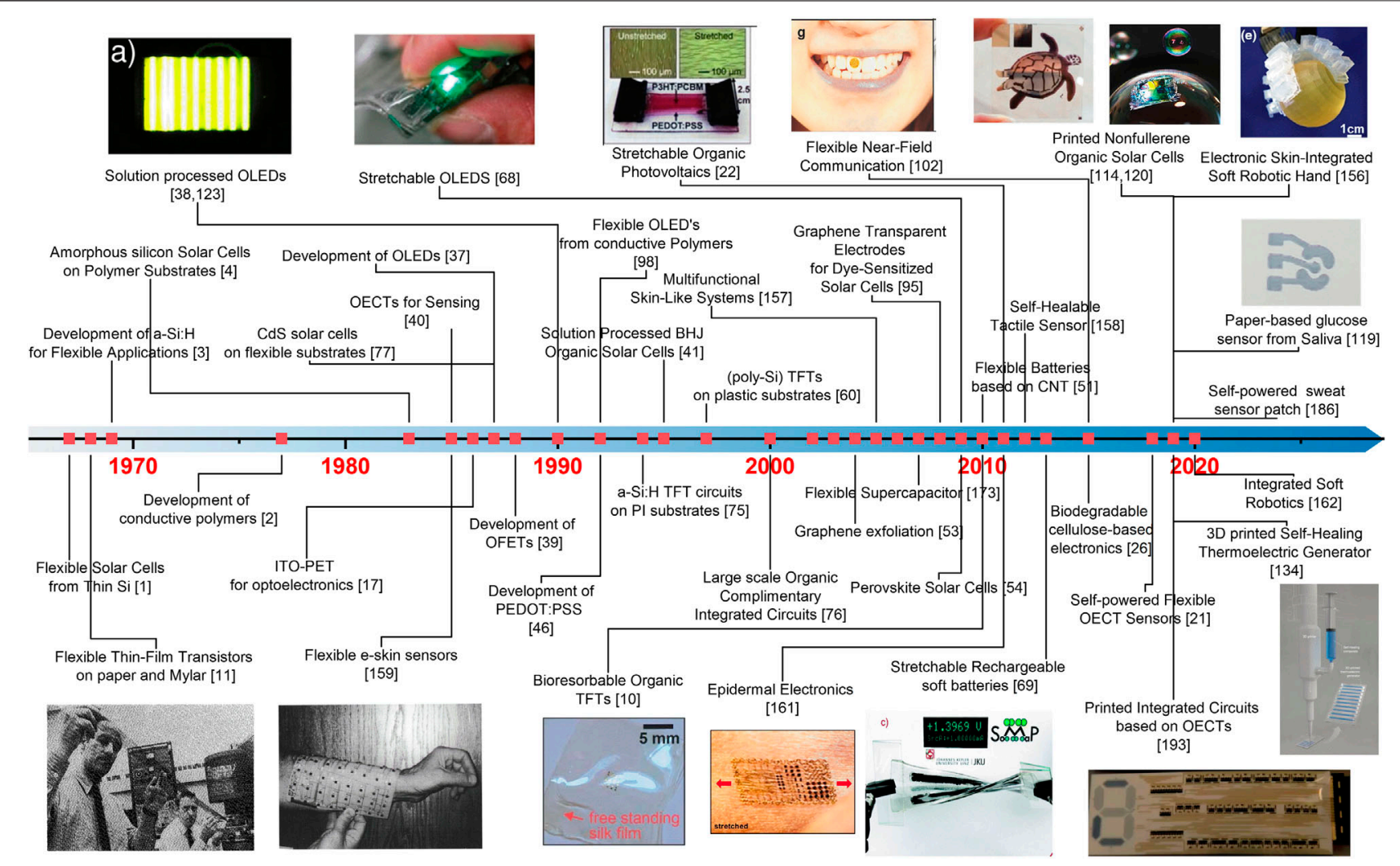

FIGURE 1 | Timeline of developments in materials, processing and applications for flexible electronics. (Reproduced with permission [11]@Copyright 1984 IEEE, [159]@Copyright 2001 IEEE, [123]@Copyright 2013 WILEY-VCH Verlag GmbH \& Co. KGaA Weinheim, [68]@Copyright 2009 Springer Nature, [10]@Copyright 2010 Society of Chemical Industry, [22]@Copyright 2011 WILEY-VCH Verlag GmbH \& Co. KGaA Weinheim, [102]@Copyright 2015 WILEY-VCH Verlag GmbH \& Co. KGaA, Weinheim, [161]@Copyright 2011 American Association for the Advancement of Science, [69]@Copyright 2013 The Royal Society of Chemistry, [114]@Copyright 2019 WILEY-VCH Verlag GmbH \& Co. KGaA Weinheim, [120]@Copyright 2020 WILEY-VCH Verlag GmbH \& Co. KGaA, Weinheim, [156]@Copyright 2019 The Authors. Published by WILEY-VCH Verlag GmbH \& Co. KGaA, Weinheim, [119]@Copyright 2018 Springer Nature, [134]@Copyright 2019 The Authors. Published by WILEY-VCH Verlag GmbH \& Co. KGaA, Weinheim, [193]@Copyright 2019 Springer Nature).

\section{MATERIALS AND METHODS}

Perhaps the first demonstrations of vacuum deposited semiconductor materials onto flexible substrates were performed at Westinghouse in the 1960s. By using paper strips instead of the rigid microscope slides, they fabricated flexible CdS thin-film transistors that could bend up to a $1 / 16$ inch radius without damage (Brody, 1984). Different challenges that need to be addressed by substrates are dependent on the application and the type of device that is fabricated on top. For instance, substrates that maximize transparency while having high bending radius, high elastic modulus, low roughness, as well as chemical stability and adequate thermomechanical properties for process compatibility, can become game changers for photovoltaic applications. Inorganic, organic and perovskite solar cells have been fabricated on polymer substrates including polyethylene terephthalate and polyethylene naphthalate which have high transmittance $(>85 \%)$, low permeability to water, and can bend up to $1^{\circ} \mathrm{mm}$ radius (Elli, 1986; Zardetto et al., 2011; Kaltenbrunner et al., 2012; Kaltenbrunner et al., 2015; Poorkazem et al., 2015; Cui et al., 2019). Polyimide has been utilized for higher processing temperatures (up to $350{ }^{\circ} \mathrm{C}$ ) (Znajdek et al., 2016; Koo et al., 2020), parylene substrates are used for conformability in biological media and ultralight applications (Park et al., 2018; Bihar et al., 2020), and elastic materials like polydimethylsiloxane have permitted stretchable solar cells (Lipomi et al., 2011; Kaltenbrunner et al., 2012).

Other devices including LEDs, electrochemical sensors, capacitors, thermoelectric generators and batteries have adapted materials like polyurethane, cellulose nanofibers, and parylene to address challenges including surface roughness, biodegradability, and compatibility with aqueous and biological media (Ummartyotin et al., 2012; Jung et al., 2015; Liu et al., 2017; Park et al., 2018; Liu Y.-F. et al., 2019). With the field moving toward personalized devices, wearables, textiles, and single-use electronics, there are inherent opportunities for substrates that can conform to different shapes, withstand the mechanical deformations of the skin and motion of the body, and can repair themselves after being damaged. Moreover, their compatibility with fabrication methods such as fast roll-to-roll printing or simple additive manufacturing techniques is imperative. 


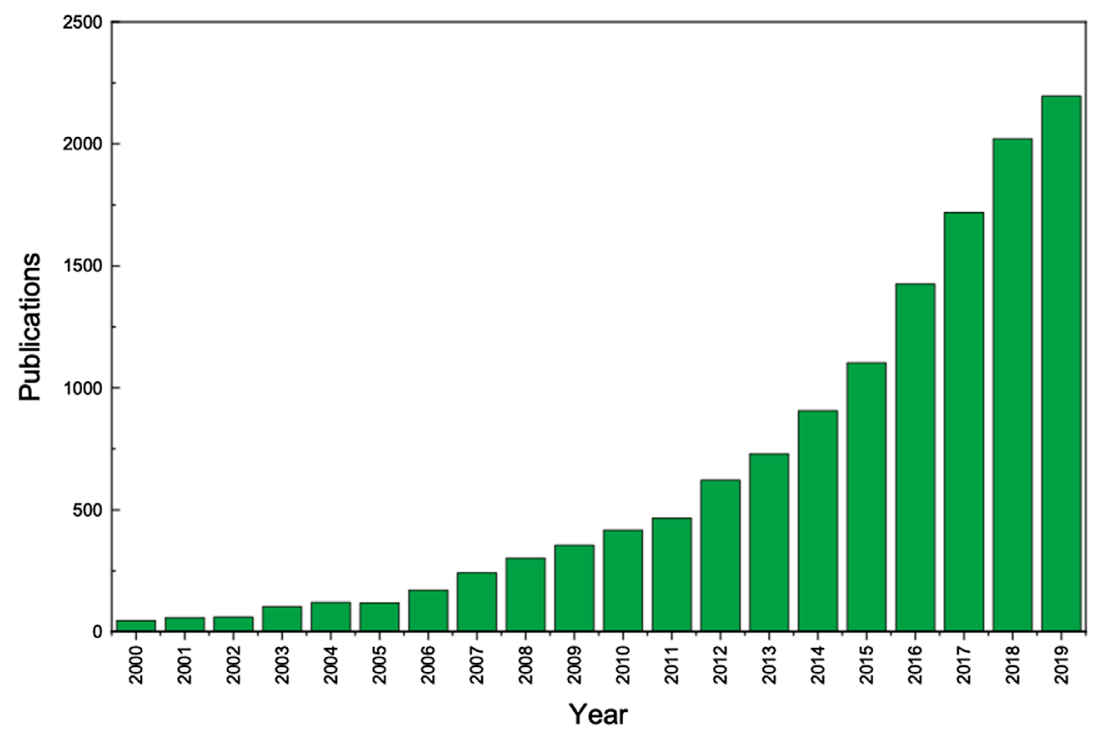

FIGURE 2 | Research publications per year obtained for the term "Flexible Electronics" on Web of science.

Among the various developed materials for functional layers and interfaces in flexible electronics, carbon-based materials (such as polymers, etc.) have been very promising in part to outstanding characteristics like conductivity, optical absorbance, charge selectivity, in addition to attractive mechanical properties like flexibility, deformability, lightweight, and the ability to be processed from solutions. 2D carbon-based materials including nanotubes and graphene have demonstrated excellent properties such as ultrahigh carrier mobility, superior electrical and thermal conductivity, high optical transmittance, large specific surface areas, favorable Young's modulus and outstanding mechanical flexibility. These promising 2D materials have been utilized to sense chemicals such as heavy metals and hazardous gases through functionalized graphene electrodes (Singh E., et al., 2017; Beduk et al., 2020a), pressure and motion based on changes in resistivity (Yamada et al., 2011; So et al., 2013; Ryu et al., 2015; Zhang Y.-Z. et al., 2018), as well as electrophysiological signals and biomarkers like chloride, lactate and glucose through the functionalization of field effect transistors and organic electrochemical transistors (Viswanathan et al., 2015; Zhang C. et al., 2018; Wustoni et al., 2019; Ohayon et al., 2020). A wide range of organic molecules (polymers, small molecules, dyes, etc.) have been synthesized and doped to increase their mobilities for their utilization in organic transistors, organic solar cells, photodetectors, and LEDs (White et al., 1984; Tang and VanSlyke, 1987; Burroughes et al., 1988; Burroughes et al., 1990; Yu et al., 1995). As they have tunable absorption and emission, they can detect and generate energy at different wavelengths of the spectrum, making them quite attractive for applications that require transparency or for the detection of X-rays for medical imaging or security, as well as to reduce the energy utilization in displays.
Organic materials like poly(3,4-ethylenedioxythiophene) polystyrene sulfonate (PEDOT:PSS) and polyaniline have demonstrated competent thermoelectric (TE) figures of merit and transport behaviors, enhanced processability into versatile forms, low density, easy synthesis, and lower costs than inorganic thermoelectric materials, which makes them perfect as energy harvesting devices from body heat (Heywang and Jonas, 1992; Cho et al., 2016; Russ et al., 2016; Du et al., 2018; Villalva et al., 2020). The porosity of PEDOT:PSS and the flaky nature of 2D materials like graphene oxide and $\mathrm{MnO}_{2}$ has been utilized to produce flexible supercapacitors and solid-state batteries with high power densities that are stable in air (Hiralal et al., 2010; Xuan et al., 2012; Liu et al., 2015; Yoon et al., 2016; Moon et al., 2020). Perhaps one of the most attractive characteristics of these organic molecules, 2D materials, as well as other hybrid organicinorganic materials like perovskites, is that they can be processed from a wide variety of solvents, and thus they can be adapted to already establish printing methodologies to produce large area devices at reduced costs (Novoselov et al., 2004; Kojima et al., 2009; Poorkazem et al., 2015; Qin et al., 2020). Despite all of these advantages, the development of accurate sensing platforms, reliable energy harvesting and storage (Qin et al., 2020), and fast and efficient displays, requires improving sensitivity, and repeatability with different fabrication methods. While doping has been used to improve the mobilities, conductivity, and TE properties of organic polymers (Villalva et al., 2020), there is still a gap for air-stable n-type organic TE materials.

The evaporation and sputtering of metals through shadow masks and photolithographic methods onto flexible substrates has been demonstrated numerously (Smith et al., 1997; Someya et al., 2004; Jain et al., 2005; Kang et al., 2008; Kaltenbrunner et al., 2013; Okita et al., 2013; Park et al., 2018). Metal oxides like indium tin oxide and fluorine-doped tin oxide are vastly utilized for optoelectronic applications due to their transparency and 
conductivity, however they offer limited flexibility due to their brittle nature (Jin et al., 2018). Thin layers of nanomaterials like graphene, carbon nanotubes, silver nanowires, and $\mathrm{Ti}_{3} \mathrm{C}_{2}$ (MXene), as well as conductive polymers like PEDOT:PSS have been fabricated through solution processing techniques and have demonstrated favorable Young's modulus while maintaining high degrees of transparency, thus becoming a viable alternative for printed optoelectronic devices (Gao, 2017; Kim et al., 2017; Liu J. et al., 2019; Kim and Alshareef, 2020; Zhang et al., 2020). In terms of interconnections, there has been a huge demonstration of metallic nanoparticles that have been dispersed in many solvents to produce printable inks for the fabrication of conductive tracks and patterns. These nanoparticles have also been included within polymeric matrices to address roughness challenges (Burgués-Ceballos et al., 2014), with elastomeric materials and hydrogels to become stretchable (Sekitani et al., 2009; Kettlgruber et al., 2013), and even alongside thermoplastic materials like polylactic acid for the production of conductive structures through fused deposition 3D printing (Tan et al., 2019). Nonetheless, many challenges to be addressed by future research include the formation of fracture paths and selfhealing as a form of mitigation, the formation of oxides and passivation pathways, as well as methods to simplify the synthesis and preparation of inks (Nayak et al., 2019). Although materials for flexible electronics are becoming smaller, stronger, lighter, cheaper, and more durable, it is crucial to consider their impact on human health and the environment. Thus, addressing biocompatibility, toxicity, and risks to the environment during processing and degradation after use will help standardize their use in wearables, e-textiles, and personalized medicine devices. Moreover, new applications will flourish as these materials become more readily available and accessible, filling the gaps where conventional rigid electronics cannot be used.

\section{Fabrication}

To produce flexible devices in a simple and efficient manner and for the different markets to adopt them, manufacturing technologies should be readily accessible, easy to use, and inexpensive. While conventional electronics are fabricated in batches through film deposition and subtractive nanofabrication methodologies including photolithography and etching, flexible and stretchable electronics are usually associated with pattern transfer, solution printing processes, roll-to-roll capabilities, and additive manufacturing technologies (Hernandez-Sosa et al., 2014; Khan et al., 2020).

A wide variety of inorganic materials, organic semiconducting molecules, and metals have been deposited or grown directly on flexible substrates through vacuum techniques including chemical vapor deposition, thermal evaporation, and atomic layered deposition to fabricate one or more layers of solar cells, LEDs, lasers, sensors, and transistors (Nair and Nair, 1987; Wu et al., 1997; Crone et al., 2000; Fang et al., 2012). However, these methods require the substrates to be cut to precision, flattened with rigid carriers, and perfectly aligned with shadow masks to pattern films correctly to avoid unwanted curvatures and strains between the different layers of the device (Cheng and Wagner, 2009). Though the thinning of rigid substrates and pattern transfer methodologies can be utilized to avoid these complications, as well as extreme processing conditions which flexible polymeric conditions cannot withstand (Linghu et al., 2018).

The thinning of silicon substrates through different procedures allows maintaining the high performance of nanofabricated integrated circuits, optoelectronics, and other devices while gaining higher bending radius, conformability, and compatibility with flexible substrates (Rojas et al., 2013; Khan et al., 2020). Thinning silicon wafers to thicknesses required for bending has been achieved in industry by removing material from the backside through grinding and polishing procedures, although issues with uniformity, substrate damage, and high material wastage are common (Rojas et al., 2013). Alternative thinning methodologies with improved control include wet and dry etching photoresistprotected wafers and dies of fully fabricated devices (Angelopoulos and Kaiser, 2011; Torres Sevilla et al., 2014; Kashyap et al., 2015), controlled exfoliation and spalling at specific depths through stress-inducing nickel layer deposition on passivated devices (Zhai et al., 2012; Shahrjerdi and Bedell, 2013), and peel-off of thin silicon-based "fabrics" through reactive etching of a sacrificial layer through pre-patterned pores (Rojas et al., 2014). These techniques have addressed standardization of the thinning process and improved material utilization, though addressing challenges including brittleness, stress induced effects, and the interface and connections with flexible electronics with different properties represent concrete opportunities in the field (Gupta et al., 2018).

The pattern transfer process uses a rigid donor substrate for the deposition of films through vacuum processes and then transfers it onto a soft target substrate through stamping (Carlson et al., 2012). For instance, the utilization of etchable sacrificial layers like silicon oxide or poly(methylmethacrylate) on wafers has allowed the fabrication of silicon optoelectronics, logic gates, and biosensors through normal lithographic methods (Kim et al., 2008). These island patterns with compressible interconnects have been transferred onto pre-stretched polydimethylsiloxane substrates which are able to flex, stretch, or conform to specific shapes, which can mimic structures like the eye for improved image capture, or adhere to soft tissue like a heart for improved direct signal acquisition (Ko et al., 2008; Kim et al., 2011). Transfer processes have also been used to pattern materials like $\mathrm{Ge} / \mathrm{Si}$ and $\mathrm{ZnO}$ nanowires (Wu et al., 2013; Yao et al., 2013), 2D monolayers like $\mathrm{MoS}_{2}$ and $\mathrm{WS}_{2}$ (Kang et al., 2015), and graphene sheets (Wang et al., 2008; Bae et al., 2010) for flexible transistors, tactile sensors, and large area transparent electrodes. Despite the versatility of this methodology, it depends on the kinetic control of the stamps, which have to create enough interface forces to peel away the material from one substrate to the other, there have been challenges to properly control the speed, contact area and sheer stresses to produce patterns (Feng et al., 2007; Chen et al., 2013). Thus, advancements in patterning, surface chemical modifications, interfacial layers to improve adhesion, and the utilization of selective and non-contact techniques will help enhance the retrieval process toward high throughput and large-scale with minimal defects (Linghu et al., 2018). 
Many of the materials discussed above can take advantage of their solution processability to efficiently produce flexible electronics in large areas and scalable factors through high throughput printing technologies (Gustafsson et al., 1992). The compatibility of flexible substrates with low temperature processing, the versatility of the functional organic and inorganic inks that are developed every day in combination with roll-to-roll (R2R) technologies is disruptively making it possible to fabricate millions of value-added technologic products at staggering speeds at economically viable costs (National Research Council, 2014). The market of printed flexible electronics for displays, sensors and consumer applications is worth $\$ 41.2$ Billion and is expected to grow to $\$ 74$ Billion by 2030 (Raghu Das and Ghaffarzadeh, 2020). Printing can be done in a variety of ways, contact and noncontact techniques are used depending on the required level of complexity and resolution of the designs, film thickness, as well as the adaptability of the inks based on rheological properties, processing temperatures, and stability. Screen printing has been utilized extensively to fabricate metallic interconnects and passive elements including resistors, capacitors and inductors for conventional printed circuit boards as well as in flexible hybrid circuits like radio frequency identification tags (Kim et al., 2015; Ostfeld et al., 2015). The utilization of graphene dispersion inks has permitted interconnects that are able to bend significantly and without much increase in their resistance after thousands of bending cycles (Song et al., 2017). This has permitted the fabrication of electrodes for thin film and ionic transistors (Song et al., 2017), antennas (Leng et al., 2016), and a variety of electrochemical sensors on paper (Cinti and Arduini, 2017). The nature of screen printing only allows thick features $(\sim 100 \mu \mathrm{m})$ from inks with high viscosity $(>500 \mathrm{cP})$, and thus it has not been used to deposit functional films in the nanometer scale. Nonetheless, thick materials for as piezoelectric generators and sensors on paper and textiles have benefited from this technique (Khan et al., 2014; Cinti and Arduini, 2017). An alternative methodology that uses stencils to create patterns is spray-coating. By controlling the different spray parameters, it has been possible to deposit and control the characteristics of thin film transistors based on carbon nanotubes (Jeong et al., 2012), ZnO (Lima et al., 2020), and organic semiconductors like 6,13-Bis(triisopropylsilylethynyl)pentacene (TIPS-Pentacene) (Yu et al., 2013) and Poly(9,9-dioctylfluorene-altbithiophene) (F8T2) (Hsu and Liu, 2014). Other functional layers fabricated through spray-coating include perovskites for solar cells (Bishop et al., 2020), MXene for strain sensors (An et al., 2018; Zhang Y.-Z. et al., 2018), and PEDOT:PSS/ Cellulose nanofibers for supercapacitors (Say et al., 2020). However, there are many challenges including resolution limits, film formation mechanisms, roughness, and material utilization that need to be addressed.

Inkjet printing is a digital fabrication process that is characterized by its ease of customization and reduced waste of materials. It has been used extensively to prototype designs and inks for flexible electronics including organic and perovskite solar cells (Mathies et al., 2018; Corzo et al., 2019; Bihar et al., 2020), PEDOT:PSS based supercapacitors (Wang Y. et al., 2018;
Manjakkal et al., 2020), gas sensing elements based on $\mathrm{ZnO}$ (Beduk et al., 2020b), a variety of organic light-emitting diodes (OLEDs), as well as a paper-based disposable glucose sensor (Bihar et al., 2018). This process builds up patterns and structures droplet by droplet, due to the high accuracy, reproducibility, and control of the volume of each droplet and the deposition area. Major challenges center around the formulation of functional inks with printable viscosity $(1-30 \mathrm{cP})$ and surface tension (20-40 dynes $/ \mathrm{cm})$ to overcome the forces at the nozzle during ejection, the utilization of particles below $200 \mathrm{~nm}$ to avoid nozzle blockages, and the selection of solvents for adhesion and uniform film formation (Hutchings and Martin, 2018; Beedasy and Smith, 2020). Nonetheless, the high-resolution, versatility, and freedom of design deems inkjet printing a simple, readily accessible, lowcost patterning alternative to photolithographic methods, opening up a huge research window for prototyping and mass-producing electronics in future applications including personalized medicine, e-textiles, wearables, and disposable electronics at a much faster rate (Gao et al., 2017).

Technologies that can be adapted to roll-to-roll processing to produce films and patterns at great speeds like blade-coating, slot die coating and gravure printing have sparked enormous amount of interest in research and industry alike. These contact processes rely on low viscosity inks $(<100 \mathrm{cP})$ being in contact with a blade that is in close proximity to the desired substrate to produce thin films $(<1 \mu \mathrm{m})$. The thickness of the films can be adjusted depending on the ink loading as well as the speed of the blade. Gravure printing on the other hand is used to produce patterns at high speeds based on a master cylinder transferring ink onto the substrate as it rolls over (Hernandez-Sosa et al., 2013). The functional layer of organic transistors, photodiodes, OLEDs and solar cells have been fabricated numerous times through bladecoating and slot-die coating, while gravure printing has been utilized to pattern graphene, carbon nanotubes, silver nanowires and indium tin oxide nanoparticles for electrodes (Alsaid et al., 2012; Noh et al., 2012; Park et al., 2015; Huang and Zhu, 2018). Nonetheless, there is still a gap in terms of scaling some materials at the quantities that are required for these methodologies. In the same manner, the industrial scalability requires the utilization of solvents that are not toxic and do not pose risks to the environment. Thus, developments in ink formulations will be crucial for their adaptation in an industrial setting.

Another methodology that has gained significant traction in the last years is $3 \mathrm{D}$ printing. While different mechanisms have been developed to render figures in 3D based on fused deposition of plastics, light curing of resin, and laser sintering of powders, printing fully functional flexible electronics is still on the horizon. There has been demonstration of embedded electronics in 3D printers by creating channels and filling them with a liquid metal to interconnect different components (Ota et al., 2016). Another strategy is the incorporation of metal nanoparticles and graphene in a PLA filament to create conductivity with the printed geometries. This has served as a base to create interconnections, resistive sensors (Kamyshny and Magdassi, 2019; Manzanares-Palenzuela et al., 2019). The same nanomaterials have been used with pastes, hydrogels, and elastomers to fabricate tactile sensors used in e-skin (Guo 
et al., 2017; Lei et al., 2017), as anode and cathode in 3D printed batteries (Park et al., 2017), and as a self-healing active in a stretchable thermoelectric generator (Kee et al., 2019). 3D printing is a relatively new field that will benefit from improved ink formulations that help build up and maintain its own weight through physical or chemical means, the exploration of new materials that will act as matrices for functional nanoparticles, as well as the engineering of new devices and means to deposit these inks to conformal surfaces and in complex shapes that may change with time.

\section{APPLICATIONS}

\section{Photovoltaics}

Solar cells position themselves as an attractive option to solve nowadays problems of finding an effective, renewable, sustainable and green energy source. They convert sun radiant energy into electrical energy according to the photovoltaic effect. At the moment, several materials have been demonstrated to be effective as the active component of said device. To date, according to the National Renewable Energy Laboratory, the highest conversion efficiency attained by silicon, perovskite, dye sensitized, III-V group-based, flexible, quantum dot, and organic solar cells are 27.6, 25.2, 12.3, 53.8, 15.38, 18.05, and 13.76\%, respectively (Ajayan et al., 2020). While totally flexible photovoltaic devices have improved, they are still not at the desired level. For instance, power conversion efficiencies of $4.2,12.85$, and $10 \%$ have been reported for ultra-flexible organic, perovskite, and quantum dot solar cells with power-per-weight output with values of 10 , 29.4, and 6.5 $\mathrm{W} \mathrm{g}^{-1}$, respectively (Kaltenbrunner et al., 2012; Zhang et al., 2017; Kang et al., 2019); demonstrating the still evident gap in efficiency when compared to devices not focused on flexibility. It is worth-noting, that in all three cases, the strategy to enhance the light weight, stretchability and stability of the device, was focused on shifting from glass substrates to more flexible polymers in junction with AgNWs. Therefore, there's still room to improve by focusing on the active layers, finding better and more suitable substrates and pinpointing cheaper and simpler processing methods in order to reach an easy scale up model. One of the most promising categories in photovoltaics, is organic solar cells, since they can and should be developed over flexible and transparent substrates and they require less energy for pre and post treatments during synthesis (Li et al., 2017; Han et al., 2019). The main challenge with these devices is to find an optimized combination between roll-to-roll processing, solution processability and improved efficiency.

\section{Bioelectronics}

A growing area in medicine, and one of the most promising ones, is bioelectronics electronics. Such medical devices can measure vital parameters of a patient noninvasively, such as heart rate (Asada et al., 2003; Schwartz et al., 2013; Jiang et al., 2019; Coffen et al., 2020), blood pressure (Pang et al., 2015; Wang et al., 2017; Rachim and Chung, 2019a, 2019b), body temperature (Seungyong Han et al., 2018; Goeckenjan et al., 2020), brain activity (Borisova et al., 2018; Ganesana et al., 2019) and specific biomarkers ( $\mathrm{pH}$, glucose, lactate) (Murat et al., 2020; Wiorek et al., 2020), to name a few. These measurements take place in real time, so they can alert individuals and physicians of the situation in order to minimize the decision-making time of a possible or necessary intervention. Flexible electronics encompass a whole array of advantages for this field, due to their stretchability, transparency and biocompatibility, useful for continuous monitoring. While all the previously listed examples focus on diagnosis and prevention, there are more fields within medicine taking advantage of wearable electronics. One of the biggest examples is prosthesis, where detecting various signals with extremely high sensitivity is required while withstanding highlevels of deformation (Kim et al., 2014; Chen et al., 2020). Artificial electronic skin and motion detection should closely mimic real interaction with the surroundings and resemble biological human skin, as well as having the ability to heal itself with occasional damage (Lumelsky et al., 2001; Engel et al., 2005; Tee et al., 2012; Yamaguchi et al., 2019). Some additional functionalities, such as humidity sensing for skin moisture sensation, thermal heating for body temperature regulation, and the ability to interface with the peripheral nervous system are some of the goals to reach in this field (Kim et al., 2011; Kenry and Lim, 2016) and should pave the way for improved soft-robotics (Oh et al., 2020). Finally, the last note-worthy field is therapy and drug delivery platforms. This kind of devices generally release the therapeutic once the system is triggered by an impulse, like sensing a specific metabolite (Bihar et al., 2018), pressure or strain (Feiner et al., 2019). The main purpose of these multiplex devices is to improve and control in a more efficient way the spatiotemporal release of the drug, so the patient receives the adequate dose (Lee et al., 2019). Regardless of the sub-field of bioelectronics, they all have a common problem: the mechanical, electrical, optical, and chemical sensing modalities have remained isolated from each other in commercial products (Heikenfeld et al., 2018); therefore, it is quite hard to get the whole outlook of the situation employing one single device. Regarding the nature of the device, some challenges to overcome are the biocompatibility of the sensor (long-term irritation to skin), impedance due to the presence of body hair, obtaining important biochemical signals with minimum invasiveness, addressing self-healability during use and extending the lifetime of the devices, as well as disposability after utilization.

\section{Energy Storage}

Nowadays is hard to find truly flexible electronics available on the market, no matter the application or field they fall under. One of the main reasons is attributed to the simple nature of the devices since most of them are considered hybrids. By that, it's meant that they are not constituted a $100 \%$ of flexible pieces. A vital part of a flexible operating electronic is the power source, or in this case, the energy storage component. Recently, there has been an increased interest in flexible energy storage in order to fulfill the demands for miniaturized, integrated and self-powered devices, flexible displays, portable electronics, healthcare and fitness-tracking devices and so forth (Park et al., 2018; Yang, 2020). Some of the challenges or needs for the transition from all- 
solid state to flexible energy storage, like low volumetric energy density (Ma et al., 2019), high internal resistance (Noelle et al., 2018) or poor mechanical durability (Pan et al., 2019), have elevated the heed in carbonaceous materials and nanocarbons to improve the already effective devices, like Li-ion batteries and supercapacitors.

It has been demonstrated that Graphene, a single layer of carbon atoms closely packed into a honeycomb twodimensional (2D) lattice (Novoselov et al., 2004), has potential for flexible electrochemical energy storage device applications due to its outstanding characteristics of chemical stability, high electrical conductivity and large surface area (Yan Wang et al., 2009). Applied into supercapacitors, it has been employed as an electrode when coupled with a wide variety of materials like cellulose (Pushparaj et al., 2007; Xing et al., 2019), polyaniline (de Souza Augusto et al., 2018; Kang et al., 2019), metallic foams (Gao et al., 2018; Manjakkal et al., 2018; Taniya Purkait, 2018) and aerogels (Bora et al., 2018) rendering overall promising results. Similarly, flexible Li-Ion batteries have also used carbon nanotubes as electrodes combined with graphene foams (Ren et al., 2018), carbon fibers (Huang et al., 2018), metal-oxides (Guo et al., 2019; Bubulinca et al., 2020) and nanoparticles (Yuan et al., 2018). In both cases, either as supercapacitors or batteries, the inclusion of the carbonbased electrode systems aided in solving some of the previously mentioned problems, as well as providing stability to the device, however, there are several challenging areas to improve: the selection and different combination of the electrode materials, electrolyte and separator in order to enhance electrochemical performance and to ensure better integrity and compatibility of said components; increasing device cycle stability; improving mechanical properties, conductivity and safety of solid-state electrolytes; optimizing cell structures; reducing toxicity and environmental impact (Li et al., 2014); and finally, developing self-powered systems (Ortega et al., 2019) to overcome all the previously mentioned limitations.

\section{Communication}

Internet of Things (IoT) is an up-and-rising concept encompassing a futuristic view of common life. It interconnects a huge number of smart devices (embedded with sensors and information transmitters) enabling machine-tomachine communication, which requires frequent data exchange and updates to the cloud without human intervention; allowing fruitful innovation areas like Smart homes, Smart Healthcare, Smart Cities, Industry and Transportation Systems (Akpakwu et al., 2018; Shi et al., 2020).

Among the diverse applications of flexible electronics, communication is one of the most relevant, since wireless technology plays a crucial role in data communication and systems control (IoT) (Cheng and Zhu, 2018). All sensors, regardless of their field, need to analyze and transmit signals or input in a fast and wireless manner. As a key component, miniaturized, flexible and stretchable antennas fulfill those needs and have gained a lot of interest in order to improve their efficiency and overcome some challenges, for instance, rigidity, deformation, obtrusion when deployed on the body, hard integration with clothing, interference with body radiation and encapsulation to prevent oxidation/corrosion (Mohamadzade et al., 2019; Zhaoqian Xie et al., 2019). Radio frequency electronics that use a passive electromagnetic device and an active electronic transistor to trigger, receive, and process information are the go-to option at the moment (Singh R. et al., 2017; Andersson Ersman et al., 2019). They employ radio frequency backscattering techniques to extract information associated with remote objects (Kiourti, 2018). The antennas act as either a transmitter or receiver to link electromagnetic waves traveling through space to electrical currents in the conductive component (Bansal, 1984), therefore, their bandwidth enhancement and size reduction are two major considerations in the design phase (Faisal, 2019). Some of the rising trends and most effective strategies to improve on antennas' performance rely on employing unusual materials structures such as serpentines and helical coils of conventional materials (Mohamadzade et al., 2019), elastomer-metallic nanoparticles composites (Song B. et al., 2018) and carbon materials like graphene (Scidà et al., 2018) and graphite (Song R. et al., 2018). Regardless of the proposed materials' solutions, a few challenges are still present on the field, mainly: designing a frequency reconfigurable flexible antenna in order to ease the integration and small volume; and finding cheaper flexible substrates that allow the different procedures for building antennas like etching and metallization (Awan et al., 2019; Goff et al., 2019; Ghaffar et al., 2020).

\section{Energy Harvesters}

As mentioned in the photovoltaics section, the latent need for an environmentally friendly power source is crucial for the development of new technologies, and while solar cells are focused toward large scale area energy harvesting, several of the other applications of flexible electronics, like wearable devices, require them to be miniaturized due to the little space available (Nan et al., 2018). Some of the strategies that have been employed rely on exploiting the forces on the ambient like thermal gradients, for development of thermoelectric harvesters (Peng et al., 2019; Zhao et al., 2019); kinetic energy in the form of vibrations or mechanical strain, for piezoelectric harvesters (Hwang et al., 2015; Wang D. et al., 2018); and finally, charging processes during friction, for triboelectric harvesters (Fan et al., 2012; Wen et al., 2018). Even though some barriers regarding the overall efficiency of these devices, like the poor output voltages and current densities of a single harvester; have been surpassed by designing hybrid systems composed of combinations of two of the three systems listed above (Kumar et al., 2019; Ji et al., 2020); some of the challenges persist, for instance: complexity of structure design, poor durability over long term exposure to repeated mechanical operation, relatively expensive fabrication process that limits large-scale production, and selection of the adequate materials in terms of mechanical and electrical properties (Qian and Kang, 2018). In addition to that, the harvesters are desired to be highly flexible so that they can easily be mounted on curved, soft surfaces in order to avoid discomfort for the user (Kim et al., 2018). 


\section{CONCLUSION}

Flexible electronics continue to evolve every day, new research is driven from functional materials with incredible form factors, to new methodologies of fabricating devices in unconventional shapes, in faster, cheaper and more accessible manners. Rather than competing with conventional electronics in terms of performance and computing power, they offer innovative ways to interact with environments that were not possible before. The future of flexible electronics includes an infinity of new applications. From harvesting energy from light through windows, cars, and clothing, as well as from the temperature gradients from our bodies and the environment, to consumer electronics like folding phones and rollable displays, to wearable and implantable bioelectronics that monitor our health and make diagnostics simpler using machine learning. The field is still a long way from delivering end products, as limitations including

\section{REFERENCES}

Ajayan, J., Nirmal, D., Mohankumar, P., Saravanan, M., Jagadesh, M., and Arivazhagan, L. (2020). A review of photovoltaic performance of organic/ inorganic solar cells for future renewable and sustainable energy technologies. Superlattice Microst. 143, 106549. doi:10.1016/j.spmi.2020.106549

Akpakwu, G. A., Silva, B. J., Hancke, G. P., and Abu-Mahfouz, A. M. (2018). A survey on $5 \mathrm{G}$ networks for the internet of things: communication technologies and challenges. IEEE Access 6, 3619-3647. doi:10.1109/access. 2017.2779844

Alsaid, D. A., Rebrosova, E., Joyce, M., Rebros, M., Atashbar, M., and Bazuin, B. (2012). Gravure printing of ITO transparent electrodes for applications in flexible electronics. J. Disp. Technol. 8 (7), 391-396. doi:10.1109/jdt.2012.2191765

An, H., Habib, T., Shah, S., Gao, H., Radovic, M., Green, J. M., et al. (2018). Surfaceagnostic highly stretchable and bendable conductive MXene multilayers. Sci. Adv. 4 (3), eaaq0118. doi:10.1126/sciadv.aaq0118

Andersson Ersman, P., Lassnig, R., Strandberg, J., Tu, D., Keshmiri, V., Forchheimer, R., et al. (2019). All-printed large-scale integrated circuits based on organic electrochemical transistors. Nat. Commun. 10 (1), 5053. doi:10.1038/s41467-019-13079-4

Angelopoulos, E. A., and Kaiser, A. (2011). "Epitaxial growth and selective etching techniques," in Ultra-thin chip technology and applications. Editor J. Burghartz (New York, NY: Springer), 53-60.

Asada, H. H., Shaltis, P., Reisner, A., Rhee, S., and Hutchinson, R. C. (2003). Mobile monitoring with wearable photoplethysmographic biosensors. IEEE Eng. Med. Biol. Mag. 22 (3), 28-40. doi:10.1109/memb.2003.1213624

Awan, W. A., Ghaffar, A., Hussain, N., and Li, X. J. (2019). "A frequency reconfigurable flexible antenna for multiple mobile applications," in IEEE Asia-Pacific microwave conference, Singapore, December 10-13, 2019 (Singapore: APMC).

Bae, S., Kim, H., Lee, Y., Xu, X., Park, J.-S., Zheng, Y., et al. (2010). Roll-to-roll production of 30-inch graphene films for transparent electrodes. Nat. Nanotechnol. 5 (8), 574-578. doi:10.1038/nnano.2010.132

Bansal, R. (1984). Antenna theory: analysis and design. Proc. IEEE 72 (7), 989-990. doi:10.1109/proc.1984.12959

Beduk, T., Ait Lahcen, A., Tashkandi, N., and Salama, K. N. (2020a). One-step electrosynthesized molecularly imprinted polymer on laser scribed graphene bisphenol a sensor. Sensor Actuat. B Chem. 314, 128026. doi:10.1016/j.snb.2020. 128026

Beduk, T., Bihar, E., Surya, S. G., Castillo, A. N., Inal, S., and Salama, K. N. (2020b). A paper-based inkjet-printed PEDOT:PSS/ZnO sol-gel hydrazine sensor. Sensor Actuat. B Chem. 306, 127539. doi:10.1016/j.snb.2019.127539

Beedasy, V., and Smith, P. J. (2020). Printed electronics as prepared by inkjet printing. Materials 13 (3), 704. doi:10.3390/ma13030704 durability, stability, and reliability in terms of device functionalities, as well as manufacturing barriers including the adaptation of equipment to developed materials and inks and balancing the initial low yield rates of new technologies with proposed investments. However, there is huge potential in bioelectronics and personalized medicine. Research that progresses the functionality and compatibility of materials with the body, sensors with improved accuracy and reliability, and the integration of multiple devices to autonomously gather, analyze, and transfer data without the need of bulky and expensive external components, will set the field at the frontiers of new products and applications.

\section{AUTHOR CONTRIBUTIONS}

All authors wrote the manuscript. DB structured the piece and made the final edits.

Bettinger, C. J., and Bao, Z. (2010). Biomaterials-based organic electronic devices. Polym. Int. 59 (5), 563-567. doi:10.1002/pi.2827

Bihar, E., Corzo, D., Hidalgo, T. C., Rosas Villalva, D., Salama, K. N., and Baran, D. (2020). Fully inkjet-printed, ultrathin and conformable organic photovoltaics as power source based on cross-linked PEDOT:PSS electrodes. Adv. Mater. Technol. 5 (8), 2000226. doi:10.1002/admt.202000226

Bihar, E., Wustoni, S., Pappa, A. M., Salama, K. N., and Lnal, S. (2018). A fully inkjet-printed disposable glucose sensor on paper. npj Flex. Electron. 2 (1), 30. doi:10.1038/s41528-018-0044-y

Bishop, J. E., Read, D. C., Smith, J. A., Routledge, T. J., and Lidzey, D. G. (2020). Fully spray-coated triple-cation perovskite solar cells. Sci. Rep. 10 (1), 6610. doi:10.1038/s41598-020-63674-5

Bora, A., Mohan, K., Doley, S., and Dolui, S. K. (2018). Flexible asymmetric supercapacitor based on functionalized reduced graphene oxide aerogels with wide working potential window. ACS Appl. Mater. Interfaces 10 (9), 7996-8009. doi:10.1021/acsami.7b18610

Borisova, T., Kucherenko, D., Kucherenko, I., Pastukhov, A., Nazarova, A., Galkin, M., et al. (2018). An amperometric glutamate biosensor for monitoring glutamate release from brain nerve terminals and in blood plasma. Anal. Chim. Acta 1022, 113-123. doi:10.1016/j.aca.2018.03.015

Brody, T. P. (1984). The thin film transistor-A late flowering bloom. IEEE Trans. Electron. Dev. 31 (11), 1614-1628. doi:10.1109/t-ed.1984.21762

Bubulinca, C., Irina, S., Kazantseva, N. E., Vilčáková, J., Cheng, Q., and Sáha, P. (2020). Fabrication of a flexible binder-free lithium manganese oxide cathode for secondary Li-ion batteries. J. Phys. Chem. Solid 137, 109222. doi:10.1016/j. jpcs.2019.109222

Burgués-Ceballos, I., Kehagias, N., Sotomayor-Torres, C. M., Campoy-Quiles, M., and Lacharmoise, P. D. (2014). Embedded inkjet printed silver grids for ITOfree organic solar cells with high fill factor. Sol. Energy Mater. Sol. Cell. 127, 50-57. doi:10.1016/j.solmat.2014.03.024

Burroughes, J. H., Bradley, D. D. C., Brown, A. R., Marks, R. N., Mackay, K., Friend, R. H., et al. (1990). Light-emitting diodes based on conjugated polymers. Nature 347 (6293), 539-541. doi:10.1038/347539a0

Burroughes, J. H., Jones, C. A., and Friend, R. H. (1988). New semiconductor device physics in polymer diodes and transistors. Nature 335 (6186), 137-141. doi:10. $1038 / 335137 \mathrm{a} 0$

Carlson, A., Bowen, A. M., Huang, Y., Nuzzo, R. G., and Rogers, J. A. (2012). Transfer printing techniques for materials assembly and micro/nanodevice fabrication. Adv. Mater. 24 (39), 5284-5318. doi:10.1002/adma.201201386

Chen, H., Feng, X., Huang, Y., Huang, Y., and Rogers, J. A. (2013). Experiments and viscoelastic analysis of peel test with patterned strips for applications to transfer printing. J. Mech. Phys. Solid. 61 (8), 1737-1752. doi:10.1016/j.jmps. 2013.04.001

Chen, Y., Liu, Y., Ren, J., Yang, W., Shang, E., Ma, K., et al. (2020). Conformable core-shell fiber tactile sensor by continuous tubular deposition modeling with 
water-based sacrificial coaxial writing. Mater. Des. 190, 108567. doi:10.1016/j. matdes.2020.108567

Cheng, H., and Zhu, J. (2018). Recent development of flexible and stretchable antennas for bio-integrated electronics. Bio-Inspiring Sensing 18 (12), 4364. doi:10.3390/s18124364

Cheng, I. C., and Wagner, S. (2009). "Overview of flexible electronics technology," in Flexible electronics: materials and applications. Editors W. S. Wong and A. Salleo (Boston, MA: Springer), 1-28.

Chittick, R. C., Alexander, J. H., and Sterling, H. F. (1969). The preparation and properties of amorphous silicon. J. Electrochem. Soc. 116 (1), 77. doi:10.1149/1. 2411779

Cho, C., Wallace, K. L., Tzeng, P., Hsu, J.-H., Yu, C., and Grunlan, J. C. (2016). Outstanding low temperature thermoelectric power factor from completely organic thin films enabled by multidimensional conjugated nanomaterials. $A d v$. Ener. Mater. 6 (7), 1502168. doi:10.1002/aenm.201502168

Cinti, S., and Arduini, F. (2017). Graphene-based screen-printed electrochemical (bio)sensors and their applications: efforts and criticisms. Biosens. Bioelectron. 89, 107-122. doi:10.1016/j.bios.2016.07.005

Coffen, B., Scott, P., and Mahmud, M. S. (2020). "Real-time wireless health monitoring: an ultra-low power biosensor ring for heart disease monitoring," in International conference on computing, networking and communications (ICNC), Big Island, United States, February 17-20, 2020.

Corzo, D., Almasabi, K., Bihar, E., Macphee, S., Rosas-Villalva, D., Gasparini, N., et al. (2019). Digital inkjet printing of high-efficiency large-area nonfullerene organic solar cells. Adv. Mater. Technol. 4 (7), 1900040. doi:10.1002/admt.201900040

Crabb, R. L., and Treble, F. C. (1967). Thin silicon solar cells for large flexible arrays. Nature 213 (5082), 1223-1224. doi:10.1038/2131223a0

Crone, B., Dodabalapur, A., Lin, Y.-Y., Filas, R. W., Bao, Z., LaDuca, A., et al. (2000). Large-scale complementary integrated circuits based on organic transistors. Nature 403 (6769), 521-523. doi:10.1038/35000530

Cui, H., Song, W., Fanady, B., Peng, R., Zhang, J., Huang, J., et al. (2019). Flexible ITO-free organic solar cells over $10 \%$ by employing drop-coated conductive PEDOT:PSS transparent anodes. Sci. China Chem. 62 (4), 500-505. doi:10. 1007/s11426-018-9426-2

de Souza Augusto, G., Scarmínio, J., Catarini Silva, P. R., de Siervo, A., Rout, C. S., Rouxinol, F., et al. (2018). Flexible metal-free supercapacitors based on multilayer graphene electrodes. Electrochim. Acta 285, 241-253. doi:10.1016/ j.electacta.2018.07.223

Dou, H. S., Kittlesen, G. P., and Wrighton, M. S. (1984). Chemical derivatization of an array of three gold microelectrodes with polypyrrole: fabrication of a molecule-based transistor. J. Am. Chem. Soc. 106 (18), 5375-5377. doi:10. 1021/ja00330a070

Du, Y., Xu, J., Paul, B., and Eklund, P. (2018). Flexible thermoelectric materials and devices. Appl. Mater. Today 12, 366-388. doi:10.1016/j.apmt.2018.07.004

Elli, D. D. (1986). Forced plasma oxidation of reactively evaporated indium as a transparent antistatic coating for ponyethylene terephthalate. Thesis. Rochester (NY): Rochester Institute of Technology

Engel, J., Chen, J., Fan, Z., and Liu, C. (2005). Polymer micromachined multimodal tactile sensors. Sensor Actuator Phys. 117 (1), 50-61. doi:10.1016/j.sna.2004.05. 037

Faisal, F., Amin, Y., Cho, Y., and Yoo, H. (2019). Compact and flexible novel wideband flower-shaped CPW-fed antennas for high data wireless applications. IEEE Trans. Antenn. Propag. 67 (6), 4184-4188. doi:10.1109/tap.2019.2911195

Fan, F.-R., Tian, Z.-Q., and Lin Wang, Z. (2012). Flexible triboelectric generator. Nano Energy 1 (2), 328-334. doi:10.1016/j.nanoen.2012.01.004

Fang, H.-H., Ding, R., Lu, S.-Y., Zhang, X.-L., Feng, J., Chen, Q.-D., and Sun, H.-B. (2012). Flexible lasers based on the microstructured single-crystalline ultrathin films. J. Mater. Chem. 22 (45), 24139-24144. doi:10.1039/c2jm35394f

Feiner, R., Wertheim, L., Gazit, D., Kalish, G., Mishal, G., Shapira, A., et al. (2019). A stretchable and flexible cardiac tissue-electronics hybrid enabling multiple drug release, sensing, and stimulation. Small 15 (14), 1805526. doi:10.1002/smll. 201805526

Feng, X., Meitl, M. A., Bowen, A. M., Huang, Y., Nuzzo, R. G., and Rogers, J. A. (2007). Competing fracture in kinetically controlled transfer printing. Langmuir 23 (25), 12555-12560. doi:10.1021/la701555n

Ganesana, M., Trikantzopoulos, E., Maniar, Y., Lee, S. T., and Venton, B. J. (2019). Development of a novel micro biosensor for in vivo monitoring of glutamate release in the brain. Biosens. Bioelectron. 130, 103-109. doi:10.1016/j.bios.2019. 01.049

Gao, L. (2017). Flexible device applications of 2D semiconductors. Small 13 (35), 1603994. doi:10.1002/smll.201603994

Gao, L., Song, J., Surjadi, J. U., Cao, K., Han, Y., Sun, D., et al. (2018). Graphenebridged multifunctional flexible fiber supercapacitor with high energy density. ACS Appl. Mater. Interfaces 10 (34), 28597-28607. doi:10.1021/ acsami.8b08680

Gao, M., Li, L., and Song, Y. (2017). Inkjet printing wearable electronic devices. J. Mater. Chem. C 5 (12), 2971-2993. doi:10.1039/c7tc00038c

Ghaffar, A., Li, X. J., Hussain, N., and Awan, W. A. (2020). "Flexible frequency and radiation pattern reconfigurable antenna for multi-band applications," in 4th Australian microwave symposium (AMS), Sydney, Australia, February 13-14, 2020.

Goeckenjan, M., Schiwek, E., and Wimberger, P. (2020). Continuous body temperature monitoring to improve the diagnosis of female infertility. Geburtshilfe Frauenheilkd 80 (7), 702-712. doi:10.1055/a-1191-7888

Goff, D. L., Song, Y., Barbier, L., and Chio, T. H. (2019). "Low-cost and highly flexible antenna for $2.4 \mathrm{GHz}$ IoT applications," in IEEE international symposium on antennas and propagation and USNC-URSI radio science meeting, Atlanta, United States, July 7-12, 2019.

Guo, S.-Z., Qiu, K., Meng, F., Park, S. H., and McAlpine, M. C. (2017). 3D printed stretchable tactile sensors. Adv. Mater. 29 (27), 1701218. doi:10.1002/adma. 201701218

Guo, W., Yan, X., Hou, F., Wen, L., Dai, Y., Yang, D., et al. (2019). Flexible and freestanding $\mathrm{SiOx} / \mathrm{CNT}$ composite films for high capacity and durable lithium ion batteries. Carbon 152, 888-897. doi:10.1016/j.carbon.2019.06.088

Gupta, S., Navaraj, W. T., Lorenzelli, L., and Dahiya, R. (2018). Ultra-thin chips for high-performance flexible electronics. npj Flex. Electron. 2 (1), 8. doi:10.1038/ s41528-018-0021-5

Gustafsson, G., Cao, Y., Treacy, G. M., Klavetter, F., Colaneri, N., and Heeger, A. J. (1992). Flexible light-emitting diodes made from soluble conducting polymers. Nature 357 (6378), 477-479. doi:10.1038/357477a0

Han, Y. W., Jeon, S. J., Lee, H. S., Park, H., Kim, K. S., Lee, H.-W., et al. (2019). Evaporation-free nonfullerene flexible organic solar cell modules manufactured by an all-solution process. Adv. Ener. Mat. 9 (42), 1902065. doi:10.1002/aenm. 201970164

Heikenfeld, J., Jajack, A., Rogers, J., Gutruf, P., Tian, L., Pan, T., et al. (2018). Wearable sensors: modalities, challenges, and prospects. Lab Chip 18 (2), 217-248. doi:10.1039/c7lc00914c

Hernandez-Sosa, G., Bornemann, N., Ringle, I., Agari, M., Dörsam, E., Mechau, N., et al. (2013). Rheological and drying considerations for uniformly gravureprinted layers: towards large-area flexible organic light-emitting diodes. $A d v$. Funct. Mater. 23 (25), 3164-3171. doi:10.1002/adfm.201202862

Hernandez-Sosa, G., Tekoglu, S., Stolz, S., Eckstein, R., Teusch, C., Trapp, J., et al. (2014). The compromises of printing organic electronics: a case study of gravure-printed light-emitting electrochemical cells. Adv. Mater. 26 (20), 3235-3240. doi:10.1002/adma.201305541

Heywang, G., and Jonas, F. (1992). Poly(alkylenedioxythiophene)s-new, very stable conducting polymers. Adv. Mater. 4 (2), 116-118. doi:10.1002/adma. 19920040213

Hiralal, P., Imaizumi, S., Unalan, H. E., Matsumoto, H., Minagawa, M., Rouvala, M., et al. (2010). Nanomaterial-enhanced all-solid flexible Zinc-Carbon batteries. ACS Nano 4 (5), 2730-2734. doi:10.1021/nn901391q

Hsu, H.-W., and Liu, C.-L. (2014). Spray-coating semiconducting conjugated polymers for organic thin film transistor applications. RSC Adv. 4 (57), 30145-30149. doi:10.1039/c4ra03726j

Huang, L., Guan, Q., Cheng, J., Li, C., Ni, W., Wang, Z., et al. (2018). Free-standing $\mathrm{N}$-doped carbon nanofibers/carbon nanotubes hybrid film for flexible, robust half and full lithium-ion batteries. Chem. Eng. J. 334, 682-690. doi:10.1016/j.cej. 2017.10.030

Huang, Q., and Zhu, Y. (2018). Gravure printing of water-based silver nanowire ink on plastic substrate for flexible electronics. Sci. Rep. 8 (1), 15167. doi:10. 1038/s41598-018-33494-9

Hutchings, I. M., and Martin, G. D. (2018). "Introduction to inkjet printing for manufacturing," in Inkjet technology for digital fabrication (United Kingdom: Inkjet Research Centre, University of Cambridge), 1-20. 
Hwang, G.-T., Byun, M., Jeong, C. K., and Lee, K. J. (2015). Flexible piezoelectric thin-film energy harvesters and nanosensors for biomedical applications. $A d v$. Healthcare Mater. 4 (5), 646-658. doi:10.1002/adhm.201400642

Irimia-Vladu, M., Troshin, P. A., Reisinger, M., Shmygleva, L., Kanbur, Y., Schwabegger, G., et al. (2010). Biocompatible and biodegradable materials for organic field-effect transistors. Adv. Funct. Mater. 20 (23), 4069-4076. doi:10.1002/adfm.201001031

Jain, K., Klosner, M., Zemel, M., and Raghunandan, S. (2005). Flexible electronics and displays: high-resolution, roll-to-roll, projection lithography and photoablation processing technologies for high-throughput production. Proc. IEEE 93 (8), 1500-1510. doi:10.1109/jproc.2005.851505

Jeong, M., Lee, K., Choi, E., Kim, A., and Lee, S.-B. (2012). Spray-coated carbon nanotube thin-film transistors with striped transport channels. Nanotechnology 23 (50), 505203. doi:10.1088/0957-4484/23/50/505203

Ji, S. H., Lee, W., and Yun, J. S. (2020). All-in-One piezo-triboelectric energy harvester module based on piezoceramic nanofibers for wearable devices. ACS Appl. Mater. Interfaces 12 (16), 18609-18616. doi:10.1021/acsami.0c02754

Jiang, C., Faroqi, L., Palaniappan, L., and Dunn, J. (2019). "Estimating personal resting heart rate from wearable biosensor data," in IEEE EMBS international conference on biomedical and health informatics (BHI), Chicago, United States, May 19-22, 2019.

Jin, S. W., Lee, Y. H., Yeom, K. M., Yun, J., Park, H., Jeong, Y. R., et al. (2018). Highly durable and flexible transparent electrode for flexible optoelectronic applications. ACS Appl. Mater. Interfaces 10 (36), 30706-30715. doi:10.1021/ acsami.8b10190

Jung, Y. H., Chang, T.-H., Yao, C., Zheng, Q., Yang, V. W., Mi, H., et al. (2015). High-performance green flexible electronics based on biodegradable cellulose nanofibril paper. Nat. Commun. 6 (1), 7170. doi:10.1038/ncomms8170

Kaltenbrunner, M., Adam, G., Głowacki, E. D., Drack, M., Schwödiauer, R., Leonat, L., et al. (2015). Flexible high power-per-weight perovskite solar cells with chromium oxide-metal contacts for improved stability in air. Nat. Mater. 14 (10), 1032-1039. doi:10.1038/nmat4388

Kaltenbrunner, M., Sekitani, T., Reeder, J., Yokota, T., Kuribara, K., Tokuhara, T., Drack, M., et al. (2013). An ultra-lightweight design for imperceptible plastic electronics. Nature 499 (7459), 458-463. doi:10.1038/nature12314

Kaltenbrunner, M., White, M. S., Glowacki, E. D., Tsuyoshi, S., Someya, T., Serdar, N., et al. (2012). Ultrathin and lightweight organic solar cells with high flexibility. Nat. Commun. 3 (1), 770. doi:10.1038/ncomms1772

Kamyshny, A., and Magdassi, S. (2019). Conductive nanomaterials for 2D and 3D printed flexible electronics. Chem. Soc. Rev. 48 (6), 1712-1740. doi:10.1039/ c8cs00738a

Kang, J., Son, D., Wang, G. J. N., Liu, Y., Lopez, J., Kim, Y., et al. (2018). Tough and water-insensitive self-healing elastomer for robust electronic skin. Adv. Mater. 30 (13), 1706846. doi:10.1002/adma.201706846

Kang, K., Xieg, S., Huangg, L., Hang, Y., Huangg, P. Y., Makg, K. F., et al. (2015). High-mobility three-atom-thick semiconducting films with wafer-scale homogeneity. Nature 520 (7549), 656-660. doi:10.1038/nature14417

Kang, M.-G., Kim, M.-S., Kim, J., and Guo, L. J. (2008). Organic solar cells using nanoimprinted transparent metal electrodes. Adv. Mater. 20 (23), 4408-4413. doi:10.1002/adma.200800750

Kang, S., Jeong, J., Cho, S., Yoon, Y. J., Park, S., Lim, S., et al. (2019). Ultrathin, lightweight and flexible perovskite solar cells with an excellent power-perweight performance. J. Mater. Chem. 7 (3), 1107-1114. doi:10.1039/ c8ta10585e

Kashyap, K., Zheng, L.-C., Lai, D.-Y., Hou, M. T., and Yeh, J. A. (2015). Rollable silicon IC wafers achieved by backside nanotexturing. IEEE Electron. Device Lett. 36 (8), 829-831. doi:10.1109/led.2015.2439701

Kee, S., Haque, M. A., Corzo, D., Alshareef, H. N., and Baran, D. (2019). Selfhealing and stretchable 3D-printed organic thermoelectrics. Adv. Funct. Mater. 29 (51), 1905426. doi:10.1002/adfm.201905426

Kenry, Y., Yeo, J. C., and Lim, C. (2016). Emerging flexible and wearable physical sensing platforms for healthcare and biomedical applications. Microsyst. Nanoeng. 2, 16043. doi:10.1038/micronano.2016.43

Kettlgruber, G., Kaltenbrunner, M., Siket, C. M., Moser, R., Graz, I. M., Schwödiauer, R., et al. (2013). Intrinsically stretchable and rechargeable batteries for self-powered stretchable electronics. J. Mater. Chem. 1 (18), 5505-5508. doi:10.1039/c3ta00019b
Khan, S., Lorenzelli, L., and Dahiya, R. S. (2014). "Screen printed flexible pressure sensors skin," in 25th annual SEMI advanced semiconductor manufacturing conference, Saratoga Springs, NY, United States (ASMC).

Khan, Y., Thielens, A., Muin, S., Ting, J., Baumbauer, C., and Arias, A. C. (2020). A new frontier of printed electronics: flexible hybrid electronics. Adv. Mater. 32 (15), 1905279. doi:10.1002/adma.201905279

Kim, C.-L., Jung, C.-W., Oh, Y.-J., and Kim, D.-E. (2017). A highly flexible transparent conductive electrode based on nanomaterials. NPG Asia Mater. 9 (10), e438. doi:10.1038/am.2017.177

Kim, D.-H., Ahn, J.-H., Choi, W. M., Kim, H.-S., Kim, T.-H., Song, J., et al. (2008). Stretchable and foldable silicon integrated circuits. Science 320 (5875), 507. doi:10.1126/science.1154367

Kim, D.-H., Lu, N., Ghaffari, R., Kim, Y.-S., Lee, S. P., Xu, L., et al. (2011). Materials for multifunctional balloon catheters with capabilities in cardiac electrophysiological mapping and ablation therapy. Nat. Mater. 10 (4), 316-323. doi:10.1038/nmat2971

Kim, H., and Alshareef, H. N. (2020). MXetronics: MXene-enabled electronic and photonic devices. ACS Mater. Lett. 2 (1), 55-70. doi:10.1021/acsmaterialslett. $9 \mathrm{~b} 00419$

Kim, J., Banks, A., Xie, Z., Heo, S. Y., Gutruf, P., Lee, J. W., et al. (2015). Miniaturized flexible electronic systems with wireless power and near-field communication capabilities. Adv. Funct. Mater. 25 (30), 4761-4767. doi:10. 1002/adfm.201501590

Kim, J., Lee, M., Shim, H. J., Ghaffari, R., Cho, H. R., Son, D., et al. (2014). Stretchable silicon nanoribbon electronics for skin prosthesis. Nat. Commun. 5 (1), 5747. doi:10.1038/ncomms6747

Kim, M.-O., Pyo, S., Oh, Y., Kang, Y., Cho, K.-H., Choi, J., et al. (2018). Flexible and multi-directional piezoelectric energy harvester for self-powered human motion sensor. Smart Mater. Struct. 27 (3), 035001. doi:10.1088/1361-665x/ aaa722

Kiourti, A. (2018). RFID antennas for body-area applications: from wearables to implants. IEEE Antenn. Propag. Mag. 60 (5), 14-25. doi:10.1109/map.2018. 2859167

Ko, H. C., Stoykovich, M. P., Song, J., Malyarchuk, V., Choi, W. M., Yu, C.-J., et al. (2008). A hemispherical electronic eye camera based on compressible silicon optoelectronics. Nature 454 (7205), 748-753. doi:10.1038/nature07113

Kojima, A., Teshima, K., Shirai, Y., and Miyasaka, T. (2009). Organometal halide perovskites as visible-light sensitizers for photovoltaic cells. J. Am. Chem. Soc. 131 (17), 6050-6051. doi:10.1021/ja809598r

Koo, D., Jung, S., Seo, J., Choi, Y., Lee, J., Lee, S. M., et al. (2020). Flexible organic solar cells over $15 \%$ efficiency with polyimide-integrated graphene electrodes. Joule 4 (5), 1021-1034. doi:10.1016/j.joule.2020.02.012

Kumar, S., Singh, H. H., and Khare, N. (2019). Flexible hybrid piezoelectricthermoelectric generator for harnessing electrical energy from mechanical and thermal energy. Energy Convers. Manag. 198, 111783. doi:10.1016/j.enconman. 2019.111783

Lee, J., Cho, H. R., Cha, G. D., Seo, H., Lee, S., Park, C.-K., et al. (2019). Flexible, sticky, and biodegradable wireless device for drug delivery to brain tumors. Nat. Commun. 10, 5205. doi:10.1038/s41467-019-13198-y

Lei, Z., Wang, Q., and Wu, P. (2017). A multifunctional skin-like sensor based on a 3D printed thermo-responsive hydrogel. Mater. Horiz. 4 (4), 694-700. doi:10. $1039 / \mathrm{c} 7 \mathrm{mh} 00262 \mathrm{a}$

Leng, T., Huang, X., Chang, K., Chen, J., Abdalla, M. A., and Hu, Z. (2016). Graphene nanoflakes printed flexible meandered-line dipole antenna on paper substrate for low-cost RFID and sensing applications. Antennas Wirel. Propag. Lett. 15, 1565-1568. doi:10.1109/lawp.2016.2518746

Li, K., Liu, X., Chn, S., Pan, W., and Zhang, J. (2019). A flexible solid-state supercapacitor based on graphene/polyaniline paper electrodes. J. Energy Chem. 32, 166-173. doi:10.1016/j.jechem.2018.07.014

Li, L., Wu, Z., Yuan, S., and Zhang, X.-B. (2014). Advances and challenges for flexible energy storage and conversion devices and systems. Energy Environ. Sci. 7 (7), 2101-2122. doi:10.1039/c4ee00318g

Li, Y., Xu, G., Cui, C., and Li, Y. (2017). Flexible and semitransparent organic solar cells. Adv. Energy Mater. 8 (7), 1701791. doi:10.1002/aenm.201701791

Lima, G. R., Braga, J. P., Gozzi, G., and Fugikawa, L.-S. (2020). On the reproducibility of spray-coated $\mathrm{ZnO}$ thin-film transistors. MRS Adv. 5 (35-36), 1859-1866. doi:10.1557/adv.2020.199 
Linghu, C., Zhand, S., Wang, C., and Song, J. (2018). Transfer printing techniques for flexible and stretchable inorganic electronics. npj Flex. Electron. 2 (1), 26. doi:10.1038/s41528-018-0037-x

Lipomi, D. J., Tee, B. C.-K., Vosgueritchian, M., and Bao, Z. (2011). Stretchable organic solar cells. Adv. Mater. 23 (15), 1771-1775. doi:10.1002/adma.201004426

Liu, H., Jian, R., Chen, H., Tian, X., Sun, C., Zhu, J., et al. (2019). Application of biodegradable and biocompatible nanocomposites in electronics: current status and future directions. Nanomaterials 9 (7), 950. doi:10.3390/nano9070950

Liu, J., Zhang, L., and Li, C. (2019). Highly stable, transparent, and conductive electrode of solution-processed silver nanowire-mxene for flexible alternatingcurrent electroluminescent devices. Ind. Eng. Chem. Res. 58 (47), 21485-21492. doi:10.1021/acs.iecr.9b04329

Liu, Y., Weng, B., Razal, J. M., Xu, Q., Zhao, C., Hou, Y., et al. (2015). Highperformance flexible all-solid-state supercapacitor from large free-standing graphene-PEDOT/PSS films. Sci. Rep. 5 (1), 17045. doi:10.1038/srep17045

Liu, Y.-F., An, M.-H., Bi, Y.-G., Yin, D., Feng, J., and Sun, H.-B. (2017). Flexible efficient top-emitting organic light-emitting devices on a silk substrate. IEEE Photon. J. 9 (5), 1-6. doi:10.1109/jphot.2017.2740618

Liu, Y.-F., Feng, J., Bi, Y.-G., Yin, D., and Sun, H.-B. (2019). Recent developments in flexible organic light-emitting devices. Adv. Mater. Technol. 4 (1), 1800371. doi:10.1002/admt.201800371

Lumelsky, V. J., Shur, M. S., and Wagner, S. (2001). Sensitive skin. IEEE Sens. J. 1 (1), 41-51. doi:10.1109/jsen.2001.923586

Ma, J., Sung, J., Hong, J., Chae, S., Kim, N., Choi, S.-H., et al. (2019). Towards maximized volumetric capacity via pore-coordinated design for large-volumechange lithium-ion battery anodes. Nat. Commun. 10 (1), 475. doi:10.1038/ s41467-018-08233-3

Manjakkal, L., Núñez, C. G., Dang, W., and Dahiya, R. (2018). Flexible selfcharging supercapacitor based on graphene-Ag-3D graphene foam electrodes. Nano Energy 51, 604-6012. doi:10.1016/j.nanoen.2018.06.072

Manjakkal, L., Pullanchiyodan, A., Yogeswaran, N., Hosseini, E. S., and Dahiya, R. (2020). A wearable supercapacitor based on conductive PEDOT:PSS-coated cloth and a sweat electrolyte. Adv. Mater. 32 (24), 1907254. doi:10.1002/adma. 201907254

Manzanares-Palenzuela, C. L., Hermanova, S., Sofer, Z., and Pumera, M. (2019). Proteinase-sculptured 3D-printed graphene/polylactic acid electrodes as potential biosensing platforms: towards enzymatic modeling of 3D-printed structures. Nanoscale 11 (25), 12124-12131. doi:10.1039/c9nr02754h

Mathies, F., Eggers, H., Richards, B. S., Hernandez-Sosa, G., Lemmer, U., and Paetzold, U. W. (2018). Inkjet-printed triple cation perovskite solar cells. ACS Appl. Energy Mater. 1 (5), 1834-1839. doi:10.1021/acsaem.8b00222

Mohamadzade, B., Hashmi, R. M., Simorangkir, R. B. V. B., Gharaei, R., Ur Rehman, S., and Abbasi, Q. H. (2019). Recent advances in fabrication methods for flexible antennas in wearable devices: state of the art. Sensors 19 (10), 2312. doi:10.3390/s19102312

Moon, I. K., Ki, B., and Oh, J. (2020). Three-dimensional porous stretchable supercapacitor with wavy structured PEDOT:PSS/graphene electrode. Chem. Eng. J. 392, 123794. doi:10.1016/j.cej.2019.123794

Murat, A., Yokus, T. S., Pozdin, V. A., Bozkurt, A., and Daniel, M. A. (2020). Wearable multiplexed biosensor system toward continuous monitoring of metabolites. Biosens. Bioelectron. 153, 112038. doi:10.1016/j.bios.2020.112038

Nair, P. K., and Nair, M. T. S. (1987). Prospects of chemically deposited Cds thin films in solar cell applications. Solar Cells 22 (2), 103-112. doi:10.1016/03796787(87)90050-0

Nan, K., Kang, S. D., Li, K., Yu, K. J., Zhu, F., Wang, J., et al. (2018). Compliant and stretchable thermoelectric coils for energy harvesting in miniature flexible devices. Sci. Adv. 4 (11), eaau5849. doi:10.1126/sciadv.aau5849

National Research Council (2014). The flexible electronics opportunity. Washington, DC: The National Academies Press, 328.

Nayak, L., Mohanty, S., Nayak, S. K., and Ramadoss, A. (2019). A review on inkjet printing of nanoparticle inks for flexible electronics. J. Mater. Chem. C 7 (29), 8771-8795. doi:10.1039/c9tc01630a

Noelle, D. J., Wang, M., Shi, Y., and Qiao, Y. (2018). Internal resistance and polarization dynamics of lithium-ion batteries upon internal shorting. Appl. Energy 212 (12), 796-808. doi:10.1016/j.apenergy.2017.12.086

Noh, J., Jung, K., Kim, J., Kim, S., Cho, S., and Cho, G. (2012). Fully gravure-printed flexible full adder using SWNT-based TFTs. IEEE Electron. Device Lett. 33 (11), 1574-1576. doi:10.1109/led.2012.2214757
Novoselov, K. S., Genim, A. K., Morozov, S. V., Jiang, D., Zhang, Y., Dubonos, S. V., et al. (2004). Electric field effect in atomically thin carbon films. Science 306, 666. doi:10.1126/science.1102896

Oh, B., Park, Y.-G., Jung, H., Ji, S., Cheong, W. H., Cheon, J., et al. (2020). Untethered soft robotics with fully integrated wireless sensing and actuating systems for somatosensory and respiratory functions. Soft Robot. [Epub ahead of print]. doi:10.1089/soro.2019.0066

Oh, J. Y., Rondeau-Gagné, S., Chiu, Y.-C., Chortos, A., Lissel, F., Wang, G.-J. N., et al. (2016). Intrinsically stretchable and healable semiconducting polymer for organic transistors. Nature 539 (7629), 411-415. doi:10.1038/nature20102

Ohayon, D., Nikiforidis, G., Savva, A., Giugni, A., Wustoni, S., Palanisamy, T., et al. (2020). Biofuel powered glucose detection in bodily fluids with an n-type conjugated polymer. Nat. Mater. 19 (4), 456-463. doi:10.1038/s41563-0190556-4

Okaniwa, H., Nakatani, K., Asano, M., Suzuki, K., Yano, M., Hirasaka, M., et al. (1983). Hydrogenated amorphous silicon solar cell on organic polymer substrate. Inst. Electron. Commun. Eng. Jpn. Trans. Sec. E Eng. 66, 34.

Okita, K., Kato, M.-N., Onoe, H., and Shoji, T. (2013). "Neurospheroid array on a flexible substrate for cortical microstimulation," in IEEE 26th international conference on micro electro mechanical systems (MEMS), Taipei, Taiwan, January 20-24, 2013, 221-224.

Ortega, L., Llorella, A., Esquivel, J. P., and Sabate, N. (2019). Self-powered smart patch for sweat conductivity monitoring. Microsyst. Nanoeng. 5 (1), 3. doi:10. 1038/s41378-018-0043-0

Ostfeld, A. E., Deckman, L., Gaikwad, A., Lochner, C. M., and Arias, A. C. (2015). Screen printed passive components for flexible power electronics. Sci. Rep. 5 (1), 15959. doi:10.1038/srep15959

Ota, H., Emaminejad, S., Gao, Y., Zhao, A., Wu, E., Challa, S., et al. (2016). Application of 3D printing for smart objects with embedded electronic sensors and systems. Adv. Mater. Technol. 1 (1), 1600013. doi:10.1002/admt.201600013

Pan, Z., Yang, J., Zhang, Q., Liu, M., Hu, Y., Kou, Z., et al. (2019). All-solid-state fiber supercapacitors with ultrahigh volumetric energy density and outstanding flexibility. Adv. Energy Mater. 9 (9), 1-10. doi:10.1002/aenm.201802753

Pang, C., Koo, J. H., Nguyen, A., Caves, J. M., Kim, M.-G., Chortos, A., et al. (2015). Highly skin-conformal microhairy sensor for pulse signal amplification. Adv. Mater. 27, 634-640. doi:10.1002/adma.201403807

Park, J. D., Lim, S., and Kim, H. (2015). Patterned silver nanowires using the gravure printing process for flexible applications. Thin Solid Films 586, 70-75. doi:10.1016/j.tsf.2015.04.055

Park, J. S., Kim, T., and Kim, W. S. (2017). Conductive cellulose composites with low percolation threshold for 3D printed electronics. Sci. Rep. 7 (1), 3246. doi:10.1038/s41598-017-03365-w

Park, S., Heo, S. W., Lee, W., Inoue, D., Jiang, Z., Yu, K., et al. (2018). Self-powered ultra-flexible electronics via nano-grating-patterned organic photovoltaics. Nature 561 (7724), 516-521. doi:10.1038/s41586-018-0536-x

Peng, J., Witting, I., Geisendorfer, N., Wang, M., Jakus, A., Kenel, C., et al. (2019). 3D extruded composite thermoelectric threads for flexible energy harvesting. Nat. Commun. 10 (1), 5590. doi:10.1038/s41467-019-13461-2

Poorkazem, K., Liu, D., and Kelly, T. L. (2015). Fatigue resistance of a flexible, efficient, and metal oxide-free perovskite solar cell. J. Mater. Chem. 3 (17), 9241-9248. doi:10.1039/c5ta00084j

Pushparaj, V. L., Shaijumon, M. M., Kumar, A., Murugesan, S., Ci, L., Vajtai, R., et al. (2007). Flexible energy storage devices based on nanocomposite paper. Proc. Natl. Acad. Sci. U.S.A. 104 (34), 13574-13577. doi:10.1073/pnas. 0706508104

Qian, Y., and Kang, D. J. (2018). Poly(dimethylsiloxane)/ZnO nanoflakes/threedimensional graphene heterostructures for high-performance flexible energy harvesters with simultaneous piezoelectric and triboelectric generation. ACS Appl. Mater. Interfaces 10 (38), 32281-32288. doi:10.1021/acsami.8b05636

Qin, J., Lan, L., Chen, S., Huaug, F., Shi, H., Chen, W., et al. (2020). Recent progress in flexible and stretchable organic solar cells. Adv. Funct. Mater. 30 (36), 2002529.

Rachim, V. P., and Chung, W.-Y. (2019a). Multimodal wrist biosensor for wearable cuff-less blood pressure monitoring system. Sci. Rep. 9, 7949. doi:10.1038/ s41598-019-44348-3

Rachim, V. P., and Chung, W.-Y. (2019b). Wearable-band type visible-near infrared zoptical biosensor for non-invasive blood glucose monitoring. Sensor Actuator. B Chem. 286, 173-180. doi:10.1016/j.snb.2019.01.121 
Raghu Das, D. X. H., and Ghaffarzadeh, K. (2020). Flexible, printed and organic electronics 2020-2030: forecasts, technologies, markets.

Ren, J., Ren, R.-P., and Lv, Y.-K. (2018). A flexible 3D graphene@CNT@MoS hybrid foam anode for high-performance lithium-ion battery. Chem. Eng. J. 353, 419-424. doi:10.1016/j.cej.2018.07.139

Rojas, J. P., Torres Sevilla, G. A., Ghoneim, M. T., Inayat, S. B., Ahmed, S. M., Hussain, A. M., et al. (2014). Transformational silicon electronics. ACS Nano 8 (2), 1468-1474. doi:10.1021/nn405475k

Rojas, J. P., Torres Sevilla, G. A., and Hussain, M. M. (2013). Can we build a truly high performance computer which is flexible and transparent? Sci. Rep. 3 (1), 2609. doi:10.1038/srep02609

Russ, B., Glaudell, A., Urban, J. J., Chabinyc, M. L., and Segalman, R. A. (2016). Organic thermoelectric materials for energy harvesting and temperature control. Nat. Rev. Mater. 1 (10), 16050. doi:10.1038/natrevmats.2016.50

Ryu, S., Lee, P., Chou, J. B., Xu, R., Zhao, R., Hart, A. J., et al. (2015). Extremely elastic wearable carbon nanotube fiber strain sensor for monitoring of human motion. ACS Nano 9 (6), 5929-5936. doi:10.1021/acsnano.5b00599

Say, M. G., Brooke, R., Edberg, J., Grimoldi, A., Belaineh, D., Engquist, I., et al. (2020). Spray-coated paper supercapacitors. npj Flex. Electron. 4 (1), 14. doi:10. 1038/s41528-020-0079-8

Schwartz, G., Tee, C.-K. B., Mei, J., Appleton, A. L., Kim, D. H., Wang, H., et al. (2013). Flexible polymer transistors with high pressure sensitivity for application in electronic skin and health monitoring. Nat. Commun. 4, 1859. doi:10.1038/ncomms 2832

Scidà, A., Haque, S., Robinson, A., Smerzi, S., Ravesi, S., Borini, S., et al. (2018). Application of graphene-based flexible antennas in consumer electronic devices. Mater. Today 21 (3), 223-230. doi:10.1016/j.mattod.2018.01.007

Sekitani, T., Nakajima, H., Maeda, H., Fukushima, T., Aida, T., Hata, K., et al. (2009). Stretchable active-matrix organic light-emitting diode display using printable elastic conductors. Nat. Mater. 8 (6), 494-499. doi:10.1038/nmat2459

Seungyong Han, J. K., Won, S. M., Ma, Y., Kang, D., Xie, Z., Lee, K.-T., et al. (2018). Battery-free, wireless sensors for full-body pressure and temperature mapping. Sci. Transl. Med. 10 (435), eaan4950. doi:10.1126/scitranslmed. aan 4950

Shahrjerdi, D., and Bedell, S. W. (2013). Extremely flexible nanoscale ultrathin body silicon integrated circuits on plastic. Nano Lett. 13 (1), 315-320. doi:10. 1021/nl304310x

Shi, W., Guo, Y., and Liu, Y. (2020). When flexible organic field-effect transistors meet biomimetics: a prospective view of the internet of things. Adv. Mater. 32 (15), 1901493. doi:10.1002/adma.201901493

Shirakawa, H., Louis, E. J., MacDiarmid, A. G., Chiang, C. K., and Heeger, A. J. (1977). Synthesis of electrically conducting organic polymers: halogen derivatives of polyacetylene, $(\mathrm{CH})_{\mathrm{x}}$. J. Chem. Soc. Chem. Commun. 1977, 578-580. doi:10.1039/c39770000578

Singh, E., Meyyappan, M., and Nalwa, H. S. (2017). Flexible graphene-based wearable gas and chemical sensors. ACS Appl. Mater. Interfaces 9 (40), 34544-34586. doi:10.1021/acsami.7b07063

Singh, R., Singh, E., and Nalwa, H. S. (2017). Inkjet printed nanomaterial based flexible radio frequency identification (RFID) tag sensors for the internet of nano things. RSC Adv. 7, 48597-48630. doi:10.1039/c7ra07191d

Smith, P. M., Carey, P. G., and Sigmon, T. W. (1997). Excimer laser crystallization and doping of silicon films on plastic substrates. Appl. Phys. Lett. 70 (3), 342-344. doi:10.1063/1.118409

So, H.-M., Sim, J. W., Kwon, J., Yun, J., Baik, S., and Chang, W. S. (2013). Carbon nanotube based pressure sensor for flexible electronics. Mater. Res. Bull. 48 (12), 5036-5039. doi:10.1016/j.materresbull.2013.07.022

Someya, T., Sekitani, T., Iba, S., Kato, Y., Kawaguchi, H., and Sakurai, T. (2004). A large-area, flexible pressure sensor matrix with organic field-effect transistors for artificial skin applications. Proc. Natl. Acad. Sci. U.S.A. 101 (27), 9966-9970. doi:10.1073/pnas.0401918101

Song, B., Wu, F., Moon, K.-S., Bahr, R., Tenzeris, M., and Wong, C. P. (2018). "Stretchable, printable and electrically conductive composites for wearable RF antennas," in IEEE 68th electronic components and technology conference (ECTC), San Diego, CA, May 29-June 1, 2018.

Song, D., Mahajan, A., Secor, E. B., Hersam, M. C., Francis, L. F., and Frisbie, C. D. (2017). High-resolution transfer printing of graphene lines for fully printed, flexible electronics. ACS Nano 11 (7), 7431-7439. doi:10.1021/acsnano. $7 \mathrm{~b} 03795$
Song, R., Wang, Q., Mao, B., Wang, Z., Tang, D., Zhang, B., et al. (2018). Flexible graphite films with high conductivity for radio-frequency antennas. Carbon 130, 164-169. doi:10.1016/j.carbon.2018.01.019

Tan, H. W., An, J., Chua, C. K., and Tran, T. (2019). Metallic nanoparticle inks for 3D printing of electronics. Adv. Electron. Mater. 5 (5), 1800831. doi:10.1002/ aelm. 201800831

Tang, C. W., and VanSlyke, S. A. (1987). Organic electroluminescent diodes. Appl. Phys. Lett. 51 (12), 913-915. doi:10.1063/1.98799

Taniya Purkait, G. S., Kumar, D., Singh, M., and Dey, R. S. (2018). Highperformance flexible supercapacitors based on electrochemically tailored three-dimensional reduced graphene oxide networks. Sci. Rep. 8, 604. doi:10. 1038/s41598-017-18593-3

Tee, B. C.-K., Wang, C., Allen, R., and Bao, Z. (2012). An electrically and mechanically self-healing composite with pressure- and flexion-sensitive properties for electronic skin applications. Nat. Nanotechnol. 7 (12), 825-832. doi:10.1038/nnano.2012.192

Torres Sevilla, G. A., Ghoneim, M. T., Fahad, H., Rojas, J. P., Hussain, A. M., and Hussain, M. M. (2014). Flexible nanoscale high-performance FinFETs. ACS Nano 8 (10), 9850-9856. doi:10.1021/nn5041608

Ummartyotin, S., Juntaro, J., Sain, M., and Manuspiya, H. (2012). Development of transparent bacterial cellulose nanocomposite film as substrate for flexible organic light emitting diode (OLED) display. Ind. Crop. Prod. 35 (1), 92-97. doi:10.1016/j.indcrop.2011.06.025

Villalva, D. R., Md. Haque, M., Nugraha, M. I., and Baran, D. (2020). Enhanced thermoelectric performance and lifetime in acid-doped PEDOT:PSS films via work function modification. ACS Appl. Energy Mater. doi:10.1021/acsaem.0c01511

Viswanathan, S., Narayanan, T. N., Aran, K., Fink, K. D., Paredes, J., Ajayan, P. M., et al. (2015). Graphene-protein field effect biosensors: glucose sensing. Mater. Today 18 (9), 513-522. doi:10.1016/j.mattod.2015.04.003

Wang, D., Yuan, G., Hao, G., and Wang, Y. (2018). All-inorganic flexible piezoelectric energy harvester enabled by two-dimensional mica. Nano Energy 43, 351-358. doi:10.1016/j.nanoen.2017.11.037

Wang, L., Jackman, J. A., Tan, E.-L., Park, J. H., Potroz, M. G., Hwang, E. T., and Cho, N.-J. (2017). High-performance, flexible electronic skin sensor incorporating natural microcapsule actuators. Nano Energy 36, 38-45. doi:10.1016/j.nanoen.2017.04.015

Wang, X., Zhi, L., and Müllen, K. (2008). Transparent, conductive graphene electrodes for dye-sensitized solar cells. Nano Lett. 8 (1), 323-327. doi:10. $1021 / \mathrm{nl} 1072838 \mathrm{r}$

Wang, Y., Shi, Z., Huang, Y., Ma, Y., Wang, C., Chen, M., et al. (2009). Supercapacitor devices based on graphene materials. J. Phys. Chem. C 113, 13103-13107. doi:10.1021/jp902214f

Wang, Y., Zhang, Y.-Z., Dubbink, D., and ten Elshof, J. E. (2018). Inkjet printing of $\delta-\mathrm{MnO}_{2}$ nanosheets for flexible solid-state micro-supercapacitor. Nano Energy 49, 481-488. doi:10.1016/j.nanoen.2018.05.002

Wen, Z., Yang, Y., Sun, N., Li, G., Liu, Y., Chen, C., et al. (2018). A wrinkled PEDOT:PSS film based stretchable and transparent triboelectric nanogenerator for wearable energy harvesters and active motion sensors. Adv. Funct. Mater. 28 (37), 1803684. doi:10.1002/adfm.201803684

Wiorek, A., Cuartero, M., and Crespo, G. A. (2020). Epidermal patch with glucose biosensor: $\mathrm{pH}$ and temperature correction toward more accurate sweat analysis during sport practice. Anal. Chem. 92 (14), 10153-10161. doi:10.1021/acs. analchem.0c02211

Wu, C. C., Theiuss, S. D., Gu, G., Lu, M. H., Sturm, J. C., Wagner, S., et al. (1997). Integration of organic LEDs and amorphous $\mathrm{Si}$ TFTs onto flexible and lightweight metal foil substrates. IEEE Electron. Device Lett. 18 (12), 609-612. doi: $10.1109 / 55.644086$

Wu, W., Wen, X., and Wang, Z. L. (2013). Taxel-addressable matrix of verticalnanowire piezotronic transistors for active and adaptive tactile imaging. Science 340 (6135), 952. doi:10.1126/science. 1234855

Wustoni, S., Savva, A., Sun, R., Bihar, E., and Inal, S. (2019). Enzyme-free detection of glucose with a hybrid conductive gel electrode. Adv. Mater. Interfaces 6 (1), 1800928. doi:10.1002/admi.201800928

Xing, J., Tao, P., Wu, Z., Xing, C., Liao, X., and Nie, S. (2019). Nanocellulosegraphene composites: a promising nanomaterial for flexible supercapacitors. Carbohydr. Polym. 207, 447-459. doi:10.1016/j.carbpol.2018.12.010

Xuan, Y., Sandberg, M., Berggren, M., and Crispin, X. (2012). An all-polymer-air PEDOT battery. Org. Electron. 13 (4), 632-637. doi:10.1016/j.orgel.2011.12.018 
Yamada, T., Hayamizu, Y., Yamamoto, Y., Yomogida, Y., Izadi-Najafabadi, A., Futaba, D. N., et al. (2011). A stretchable carbon nanotube strain sensor for human-motion detection. Nat. Nanotechnol. 6 (5), 296-301. doi:10.1038/ nnano.2011.36

Yamaguchi, T., Kashiwagi, T., Arie, T., Akita, S., and Takei, K. (2019). Human-like electronic skin-integrated soft robotic hand. Adv. Intell. Syst. 1 (2), 1900018. doi:10.1002/aisy.201900018

Yang, Y. (2020). A mini-review: emerging all-solid-state energy storage electrode materials for flexible devices. Nanoscale 12, 3560-3573. doi:10.1039/ c9nr08722b

Yao, J., Yan, H., and Lieber, C. M. (2013). A nanoscale combing technique for the large-scale assembly of highly aligned nanowires. Nat. Nanotechnol. 8 (5), 329-335. doi:10.1038/nnano.2013.55

Yoon, D. H., Yoon, S. H., Ryu, K. S., and Park, Y. J. (2016). PEDOT:PSS as multifunctional composite material for enhanced Li-air-battery air electrodes. Sci. Rep. 6 (1), 19962. doi:10.1038/srep19962

Yu, G., Gao, J., Hummelen, J. C., Wudl, F., and Heeger, A. J. (1995). Polymer photovoltaic cells: enhanced efficiencies via a network of internal donoracceptor heterojunctions. Science 270 (5243), 1789-1791. doi:10.1126/ science.270.5243.1789

Yu, X., Zhou, N., Han, S., Lin, H., Buchholz, D. B., Yu, J., et al. (2013). Flexible spray-coated TIPS-pentacene organic thin-film transistors as ammonia gas sensors. J. Mater. Chem. C 1 (40), 6532-6535. doi:10.1039/c3tc31412j

Yuan, W., Wang, B., Wu, H., Xiang, M., Wang, Q., Liu, H., et al. (2018). A flexible 3D nitrogen-doped carbon foam@CNTs hybrid hosting TiO2 nanoparticles as free-standing electrode for ultra-long cycling lithium-ion batteries. J. Power Sources 379, 10-19. doi:10.1016/j.jpowsour.2018.01.023

Zardetto, V., Brown, T. M., Reale, A., and Di Carlo, A. (2011). Substrates for flexible electronics: a practical investigation on the electrical, film flexibility, optical, temperature, and solvent resistance properties. J. Polym. Sci. B Polym. Phys. 49 (9), 638-648. doi:10.1002/polb.22227

Zhai, Y., Mathew, L., Rao, R., Xu, D., and Banerjee, S. K. (2012). High-performance flexible thin-film transistors exfoliated from bulk wafer. Nano Lett. 12 (11), 5609-5615. doi:10.1021/nl302735f
Zhang, C., Zhang, Z., Yang, Q., and Chen, W. (2018). Graphene-based electrochemical glucose sensors: fabrication and sensing properties. Electroanalysis 30 (11), 2504-2524. doi:10.1002/elan.201800522

Zhang, X., Oberg, V. A., Du, J., Liu, J., and Johansson, E. M. J. (2017). Extremely lightweight and ultra-flexible infrared light converting quantum dot solar cells with high power-per-weight output using a solution-processed bending durable silver nanowire based electrode. Energy Environ. Sci. 11, 354. doi:10.1039/C7EE02772A

Zhang, Y.-Z., Lee, K. H., Anjum, D. H., Sougrat, R., Jiang, Q., Kim, H., et al. (2018) MXenes stretch hydrogel sensor performance to new limits. Science Advances 4 (6), eaat0098. doi:10.1126/sciadv.aat0098

Zhang, Y.-Z., Wang, Y., Jiang, Q., El-Demellawi, J. K., Kim, H., and Alshareef, H. N. (2020). MXene printing and patterned coating for device applications. Adv. Mater. 32 (21), 1908486. doi:10.1002/adma.201908486

Zhao, X., Han, W., Zhao, C., Wang, S., Kong, F., Ji, X., et al. (2019). Fabrication of transparent paper-based flexible thermoelectric generator for wearable energy harvester using modified distributor printing technology. ACS Appl. Mater. Interfaces 11 (10), 10301-10309. doi:10.1021/acsami.8b21716

Zhaoqian Xie, R. A., Huang, Y., and Rogers, J. A. (2019). Flexible and stretchable antennas for biointegrated electronics. Adv. Mater. 32 (15), 1-16. doi:10.1002/ adma.20190276

Znajdek, K., Sibiński, M., Strąkowska, A., and Lisik, Z. (2016). Polymer substrates for flexible photovoltaic cells application in personal electronic system. OptoElectron. Rev. 24 (1), 20. doi:10.1515/oere-2016-0001

Conflict of Interest: The authors declare that the research was conducted in the absence of any commercial or financial relationships that could be construed as a potential conflict of interest.

Copyright (c) 2020 Baran, Corzo and Blazquez. This is an open-access article distributed under the terms of the Creative Commons Attribution License (CC $B Y)$. The use, distribution or reproduction in other forums is permitted, provided the original author(s) and the copyright owner(s) are credited and that the original publication in this journal is cited, in accordance with accepted academic practice. No use, distribution or reproduction is permitted which does not comply with these terms. 